\title{
Laboratory-based clinical audit as a tool for continual improvement: an example from CSF chemistry turnaround time audit in a South-African teaching hospital
}

Lucius C Imoh, Mubanga Mutale, Christopher T Parker, Rajiv T Erasmus, Annalise E Zemlin*

Department of Chemical Pathology, Tygerberg Hospital, National Health Laboratory Service (NHLS) and University of Stellenbosch, Cape Town, South Africa

${ }^{*}$ Corresponding author: azemlin@sun.ac.za

\begin{abstract}
Introduction: Timeliness of laboratory results is crucial to patient care and outcome. Monitoring turnaround times (TAT), especially for emergency tests, is important to measure the effectiveness and efficiency of laboratory services. Laboratory-based clinical audits reveal opportunities for improving quality. Our aim was to identify the most critical steps causing a high TAT for cerebrospinal fluid (CSF) chemistry analysis in our laboratory.

Materials and methods: A 6-month retrospective audit was performed. The duration of each operational phase across the laboratory work flow was examined. A process-mapping audit trail of 60 randomly selected requests with a high TAT was conducted and reasons for high TAT were tested for significance.

Results: A total of 1505 CSF chemistry requests were analysed. Transport of samples to the laboratory was primarily responsible for the high average TAT (median TAT $=170$ minutes). Labelling accounted for most delays within the laboratory (median TAT $=71$ minutes) with most delays occurring after regular work hours $(P<0.05)$. CSF chemistry requests without the appropriate number of CSF sample tubes were significantly associated with delays in movement of samples from the labelling area to the technologist's work station (caused by a preference for microbiological testing prior to (SF chemistry).

Conclusion: A laboratory-based clinical audit identified sample transportation, work shift periods and use of inappropriate CSF sample tubes as drivers of high TAT for CSF chemistry in our laboratory. The results of this audit will be used to change pre-analytical practices in our laboratory with the aim of improving TAT and customer satisfaction.
\end{abstract}

Key words: turnaround time; laboratory audit; quality indicator; continual improvement; CSF chemistry

\section{Introduction}

Laboratory-based clinical audit is an important process in obtaining feedback for continual improvement. It involves measuring laboratory performance using selected quality indicators and defined benchmarks $(1,2)$. Audits in the laboratory are used to determine the root cause of non-conformities and assess the effectiveness of changes made.

Timeliness of laboratory results as a quality indicator assesses the effectiveness and efficiency of the total testing process and is expressed as turna- round time (TAT) for laboratory tests (3-5). The impact of TAT on the hospital length of stay is well documented $(6,7)$. It is also crucial to clinicians' and patients' satisfaction as highlighted in College of American Pathologists (CAP) Q-probes surveys $(8,9)$.

An improvement of TAT may require increased manpower and use of sophisticated equipment with greater throughput and this is often not practical, especially in low income settings (10-12). Lean management of TAT, by redesigning the existing 
work flow to utilize time efficiently, is often necessary for addressing challenges of high TAT. Understanding the root causes of high TAT using evidence-based methods is therefore imperative for planning improvements. Consequently, regulatory and accrediting bodies advise clinical laboratories to target TAT in their continual improvement process (13-15).

The implications of untimely laboratory results are perhaps better observed with emergency tests such as potassium, cardiac troponins and cerebrospinal fluid (CSF) chemistry. Delayed CSF results may result in grave consequences, especially in the setting of acute neurological diseases. Additionally, concerns about the stability of CSF analytes further underscore the need for rapid analysis (16-18). Sample transport and other pre-analytical processes are known to affect TAT $(2,19)$. The origin of the sample, for example inpatient versus outpatient, may also influence the TAT (20).

CSF chemistry presents a unique challenge for improvement of TAT, as it is one of the few panel tests ordered as an emergency request. CSF glucose, protein, chloride and microbiology are most often requested to diagnose suspected neurological infections $(21,22)$. The complete set of CSF results is usually required prior to reporting for sensible interpretation and this may affect the TAT. Samples are often shared between different sections of the laboratory such as microbiology and chemistry, leading to increased TAT.

Recent increases in our laboratory's workload have had an expected adverse impact on TAT, including that of CSF chemistry requests. By means of a systematic audit, our goal was to use data spanning six months to identify the most important steps that cause high TAT for CSF chemistry analysis in our laboratory and investigate the factors responsible. The results of this study will be used as a basis for improving TAT.

\section{Materials and Methods}

\section{Study design}

This retrospective audit was conducted on requests for a CSF chemistry panel during a 6-month period from November $1^{\text {st }} 2014$ to April 30 th 2015 at the chemical pathology laboratory of Tygerberg Hospital, a tertiary referral teaching hospital in Cape Town, South Africa. The laboratory provides diagnostic pathology services to the teaching hospital as well as regional hospitals and clinics and processes an average of 90,000 tests a month.

The laboratory offers CSF protein, glucose and chloride analysis routinely as a panel. Other biochemical tests such as lactate or adenosine deaminase are performed at special request. Requests for CSF chemistry and microbiology are often accompanied by the following CSF samples: one fluoride tube (glucose), one plain tube (protein and chloride) and another plain tube (microbiology). Occasionally, only one plain tube accompanies the request in which case microbiological analysis is given preference (due to potential contamination), after which the sample is retrieved for CSF protein and chloride analysis. These were recorded as non-conformities and data from these specimens were included in this study.

CSF samples from within the hospital are transported to the laboratory central reception by the pneumatic tube system or are brought directly by hospital porters, physicians or patients' relatives. Samples from regional hospitals and clinics are brought by special couriers. Work hours in laboratory reception are divided into three shifts: (i) regular shift (8 am to $4: 30 \mathrm{pm}$ ), (ii) evening shift (4:30 pm to $8 \mathrm{pm}$ ), and (iii) night shift (8 pm to $8 \mathrm{am}$ ).

\section{Methods}

Samples go through the processes of sorting, registration and labelling followed by immediate transport to the laboratory for analysis. The result of analysis is available for the clinicians after review and authorization through the laboratory information system (LIS). The laboratory aims to fasttrack all STAT samples (including CSF samples) and to release the results within two hours. Emergency samples are marked as "STAT" and given preference through all the phases of the testing cycle.

The LIS, DISA*LAB ${ }^{\oplus}$ (Laboratory System Technologies (Pty) Ltd, Cape Town, South Africa) captures information at relevant time points determined by 
the operational workflow of the laboratory. The information extracted from the LIS was used to compute the TAT to reflect the four operational periods, described in Table 1.

Requests, especially from external hospitals and those with missing entries or errors in the date or time, were excluded. Missing entries or errors occurred whenever the laboratory staff at any operational point failed to register the appropriate sample details on the LIS. The total TAT refers to the time from collection of sample to the time of authorization in the laboratory, whereas the withinlaboratory TAT refers to the time from receipt at laboratory reception to authorization of final result. The TATs of CSF chemistry (a STAT test) and plasma glucose (a routine test) were compared to determine if the measures put in place to fast track STAT samples in our laboratory were successful. Routine plasma glucose was used in this study since glucose is also a component of CSF panel. The agreed TAT for routine glucose in our laboratory is 120 minutes.

A focused group discussion (FGD), involving technologists and the laboratory manager, was used to identify potential reasons for the high TAT. Each participant was asked to give their views as to the cause of the high TAT and the three most common

TABLE 1. Description of operational periods for CSF

\begin{tabular}{ccc}
\hline $\begin{array}{c}\text { Operational } \\
\text { period }\end{array}$ & $\begin{array}{c}\text { Period start } \\
\text { point }\end{array}$ & $\begin{array}{c}\text { Period end } \\
\text { point }\end{array}$ \\
\hline $\begin{array}{c}\text { Sample } \\
\text { transportation }\end{array}$ & $\begin{array}{c}\text { Time request } \\
\text { made on LIS }\end{array}$ & $\begin{array}{c}\text { Time sample } \\
\text { received in } \\
\text { laboratory }\end{array}$ \\
$\begin{array}{c}\text { Sample sorting and } \\
\text { registration }\end{array}$ & $\begin{array}{c}\text { Time sample } \\
\text { received in } \\
\text { laboratory }\end{array}$ & $\begin{array}{c}\text { Time sample } \\
\text { registered on LIS }\end{array}$ \\
$\begin{array}{c}\text { Sample processing } \\
\text { (labelling, movement } \\
\text { to analyser and } \\
\text { analysis) }\end{array}$ & $\begin{array}{c}\text { Time sample } \\
\text { registered on LIS }\end{array}$ & $\begin{array}{c}\text { Time result } \\
\text { authorised by } \\
\text { technologist }\end{array}$ \\
& Time result & $\begin{array}{c}\text { Time result } \\
\text { reported by } \\
\text { Reporting }\end{array}$ \\
& $\begin{array}{c}\text { authorised by } \\
\text { technologist }\end{array}$ & \begin{tabular}{c} 
phathologist \\
\hline
\end{tabular} \\
\hline
\end{tabular}

LIS - laboratory information system. reasons were noted. Sixty cases with above median TAT for the identified operational period were randomly selected. Thereafter, an audit trail was conducted on the LIS to closely examine the selected cases by breaking down the TAT of the identified period into smaller operational phases.

The operational period with the highest TAT ("sample processing") consisted of three sub-phases namely:

(i) Labelling (sample registration time to the time the label was printed)

(ii) Transport to work area (time the label was printed to time of sample entry at workstation)

(iii) Actual analysis (time of sample entry at workstation to time result was authorized by technologist).

The time of entry at work station was missing for two samples, affecting calculation of TAT for "transport to work area" and "analysis" phases so these were excluded in the test for significance for the possible reasons for high TAT.

The study was approved by the Ethics Committee of the University of Stellenbosch (N15/05/039) and carried out according to the Declaration of Helsinki. A waiver of consent was obtained as the study was retrospective and no patient results were used. Patient confidentiality was maintained at all times.

\section{Statistical analysis}

Data from DISA*LAB was exported to Microscoft Excel $^{\circledR}$ 2013, version 15.0. Thereafter, analysis was done using Statistical Package for Social Sciences (SPSS ${ }^{\bullet}$ version 15.0. SPSS inc Chicago, USA). Assessment of normality of data was done using the Shapiro-Wilk test at $P<0.05$ significance level. TAT was expressed as median with interquartile range and 90\% completion time (TAT within which $90 \%$ of tests are completed) $(9,19)$. The relationship between high TAT and the suggested responsible factors was tested for significance using Fisher's exact test (23). A P $<0.05$ was considered significant. 


\section{Results}

Within the period under review a total of 2093 CSF requests were received. After excluding 588 requests with missing entries or errors (involving time and date records), 1505 requests were analysed. The median total and within-laboratory TATs were 345 minutes and 147 minutes, respectively. As a percentage of the total and within-laboratory TAT, sample transportation accounted for most delays with a median of $53.4 \%$ of the total TAT, whilst the period of sample processing accounted for a median of $65.5 \%$ of the within-laboratory TAT. The distribution of the TAT is summarized in Table 2.

The median duration of each process across the operational workflow for CSF chemistry was compared to that of plasma glucose (Figure 1). Although CSF chemistry had higher median transportation and total TAT, registration and withinlaboratory TAT was lower compared to plasma glucose. The median TAT for sample processing period however was almost identical.

An audit trail of 60 randomly selected cases with above median sample processing TAT showed that labelling had the highest TAT with a median of 71 minutes whilst transport to work area had the lowest duration with a median of 10 minutes (Table 3 ).

Sample processing at non-regular work hours (affecting labelling), sample sharing for chemistry and microbiological testing (affecting transport of sample to work station) and repeat testing for specimens with critical values (affecting the analytical phase) were the most common reasons given for the high sample processing TAT as obtained

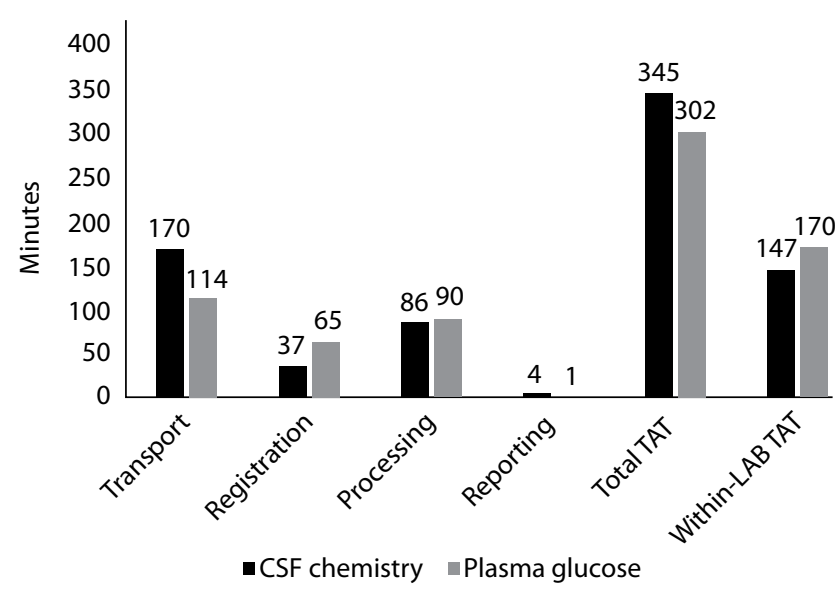

FIGURE 1. Median TAT across phases of workflow for CSF chemistry and plasma glucose. TAT - turnaround time.

TABLE 3. Summary of the distribution of TAT across the "sample processing" phases (for sixty requests with the highest TAT)

\begin{tabular}{lccc}
\hline & $\begin{array}{c}\text { Labelling } \\
\mathbf{N}=\mathbf{6 0}\end{array}$ & $\begin{array}{c}\text { Transport to } \\
\text { work station } \\
\mathbf{N = 5 8 *}\end{array}$ & $\begin{array}{c}\text { Analysis } \\
\mathbf{N = 5 8 *}\end{array}$ \\
\hline $\begin{array}{l}\text { Median } \\
\text { (minutes) }\end{array}$ & 71 & 10 & 39 \\
$\begin{array}{l}\text { Interquartile } \\
\text { range (minutes) } \\
\begin{array}{l}90 \% \text { completion } \\
\text { time (minutes) }\end{array}\end{array}$ & $46-111$ & $6-26$ & $24-65$ \\
\hline
\end{tabular}

*Two samples had no record of receipt time at work station and were excluded from this analysis

TABLE 2. Summary of the distribution of TAT across phases of work flow for 1505 CSF chemistry requests

\begin{tabular}{lcccccc}
\hline & Transport & Registration & Processing & Reporting & $\begin{array}{c}\text { Within } \\
\text { laboratory TAT }\end{array}$ & Total TAT \\
\hline Median (minutes) & 170 & 37 & 86 & 4 & 147 & 345 \\
Median \% of total TAT & 53 & 11 & 28 & 1 & 47 & - \\
Median \% of within-laboratory TAT & - & 27 & 66 & 3 & - & $248-484$ \\
Interquartile range (minutes) & $108-277$ & $20-67$ & $62-126$ & $2-11$ & 30 & 305 \\
$90 \%$ completion time (minutes) & 421 & 113 & 188 & 666 \\
\hline
\end{tabular}

TAT - turnaround time. 
from the FGD. Amongst the 60 cases, repeat testing in 34 cases (34 / 60) and shared CSF sample in only 4 (4 / 60) cases were observed. Equal numbers of cases (26/60) occurred during regular hours and the night shift (Table 4).

The work shift was significantly associated with the highest quartile of TAT for the labelling pro-

TABLE 4. "Proposed reasons for long TAT" and the upper quartile of TAT for "labelling", "transportation to work area" and "analysis" phases

\begin{tabular}{ccc}
$\leq 75^{\text {th }}$ & $>75^{\text {th }}$ & \\
percentile & percentile & Total \\
TAT & TAT & \\
\hline
\end{tabular}

\begin{tabular}{lcccc}
\hline I. Sample labelling & & & & \\
\hline Work shift & & 2 & 26 & \\
Regular hours & 24 & 4 & 8 & 0.012 \\
Evening hours & 4 & 9 & 26 & \\
Night hours & 17 & &
\end{tabular}

\begin{tabular}{lcccc}
\hline II. Transportation to work area & & & \\
\hline Work Shift & 17 & 8 & 25 & \\
Regular hours* & 5 & 2 & 7 & 0.369 \\
$\begin{array}{l}\text { Evening hours* } \\
\text { Night hours }\end{array}$ & 22 & 4 & 26 & \\
$\begin{array}{l}\text { Shared CSF } \\
\text { sample }\end{array}$ & & & & \\
Shared sample* & 0 & 3 & 3 & \\
$\begin{array}{l}\text { No shared } \\
\text { sample *十 }\end{array}$ & 38 & 10 & 48 & 0.001 \\
\hline
\end{tabular}

\begin{tabular}{lcccc}
\hline III. Analysis phase & & & & \\
\hline Work shift & 19 & 6 & 25 & \\
Regular hours* & 5 & 2 & 7 & 1.000 \\
$\begin{array}{l}\text { Evening hours* } \\
\text { Night hours }\end{array}$ & 20 & 6 & 26 & \\
$\begin{array}{l}\text { Repeat testing } \\
\text { Repeat testing* }\end{array}$ & 19 & 6 & 25 & \\
$\begin{array}{l}\text { No repeat } \\
\text { testing* }\end{array}$ & 25 & 8 & 33 & 1.000 \\
\hline
\end{tabular}

*one of the two missing data for time of receipt at work station which affected computing of TAT for transport to work area and Analysis phases (see Table 2).

† Seven requests missing record of number of tubes.

TAT - turnaround time.

$\mathrm{P}<0.05$ considered statistically significant. cess but not for "movement to work station" or "analysis" phases. Compared to the regular working shift, a higher proportion of CSF samples labelled during the evening and night shift were likely to be in the upper quartile for TAT of this work phase (Table 3). Also, all cases of shared CSF sample were in the upper quartile of TAT for the phase of "transport to work station" compared to 10 (10 / 48) to non-shared sample. Repeat testing was not significantly associated with the upper quartile TAT for analysis phase (Table 4).

\section{Discussion}

Our audit showed that the median within-laboratory TAT in our laboratory for CSF chemistry (147 min) and routine glucose (170 $\mathrm{min}$ ) exceeded our target TAT (120 min). This is contrary to findings of a national survey on intra-laboratory TAT for some common routine and STAT laboratory analyses performed in 479 laboratories in China which found the median within-laboratory TAT for stat and routine glucose to be $45 \mathrm{~min}$ and $130 \mathrm{~min}$, respectively (24).

We applied a systematic outlier analysis to identify reasons for the high TAT in our laboratory by analysing the requests with the highest TATs (above the median within-laboratory TAT; $147 \mathrm{~min}$ ). A CAP Q-Probes study applied a similar approach by analysing outlier TAT events to help determine the causes of delays in the TAT process for STAT tests from emergency departments and intensive care units. However, they used an arbitrarily chosen 70-minute TAT to define outliers (25).

The breakdown of the TAT of CSF chemistry requests in our laboratory identified transport of sample to the laboratory as the main culprit for high total TAT. A delayed transport of samples to the laboratory impacts negatively on the quality of laboratory results (26). The increasing need for laboratories to become more involved in pre-preanalytical issues has been emphasized (27). Furthermore, the role of inappropriate sampling on CSF chemistry TAT in this study underscores the importance of sample collection and handling on the quality of laboratory output, as highlighted in the recently harmonized list of quality indicators (28). 
Suggestions from interviews of laboratory staff identified the sharing of samples with the microbiology laboratory as the main cause of high TAT for CSF chemistry. Findings from this study revealed that whilst this is a contributory factor, it accounted for at most 7\% of the cases of high TAT and only impacted on the "transport to work area" phase of "sample processing". This highlights the fact that changes in laboratory operations that are not evidence-based may have little impact whilst damaging root causes may be missed. This phase of laboratory operation could be improved by educating clinicians on the need for appropriate sampling.

Our TAT for the reporting phase for CSF chemistry was within recommended 6 minutes suggested by Ricos et al. (29). We also found that efforts to fasttrack the pre-analytical handling of emergency samples like CSF are effective for the registration phase as evidenced by the shorter median duration of this period for CSF chemistry when compared with plasma glucose. The sample processing phase however, appears to have an identical TAT for both tests. We expected a considerably lower TAT for CSF chemistry, as this is a STAT test, when compared to a routine test such as plasma glucose. Our findings demonstrate that sample processing was responsible for most of the withinlaboratory TAT.

Our process-mapping investigation of the "sample processing" phase TAT indicated that samples were processed more slowly during evening and night work hours. This is contrary to a study from Pakistan which found that more delays in TAT of STAT tests occurred in the morning shift (30). The delays in TAT in relation to work schedule have been suggested to be due to an imbalance between workload and staffing $(24,30)$. In our laboratory, this is particularly noticeable as it affects labelling of samples which is a time-consuming manual process. Therefore, the TAT for labelling is closely related to the number of staff available to perform the task. Although the sample throughput is generally expected to be lower during evening and night shifts, this period also coincides with the arrival of samples from remote peripheral hospitals. Our findings suggest a review in workforce distribution is necessary.
Although the analytical phase TAT was not significantly affected by repeat testing for critical concentrations, the frequency of occurrence of repeat testing for CSF chemistry is a concern. Apart from the unnecessary consumption of reagents and extensive additional workload, the impact on TAT for an individual request may not be easily quantified. A previous study in our laboratory found that there was no significant difference between values obtained at initial testing and those from repeat testing for critical concentrations (31).

A limitation of our study is that we were unable to objectively determine whether addressing the causes of high TAT identified in this study will reduce the TAT. This will require follow-up and re-audit after instituting the suggested changes. Additionally, the number of cases in the regular, evening and night shifts may have been disproportional given the difference in duration of the shifts. A further limitation is that due to time constraints, only 60 cases with high TAT were analysed. Analysis of a larger number may have revealed more causes of high TAT. The reliability of our results may have been affected by the exclusion of over a quarter of our samples due to missing entries or errors. Entry at work station time was recorded manually by the technologists on the bench. Nonconformities in entering this time point were responsible for some missing calculations. Also, the CSF chemistry TAT was not compared with TAT of other STAT tests.

Despite these limitations, our study has demonstrated how systematic laboratory audits can be applied as a tool for root-cause analysis of problems in the clinical laboratory, particularly as it relates to TAT. Our study provides evidence that can be used as a basis for making relevant changes to public laboratory services. The National Health Laboratory Service (NHLS) has established guidelines stating the acceptable TAT for all tests covered by their service. However, the NHLS did not specify TAT for analysis of CSF chemistry as a distinct sample, which could be useful considering the unique challenge of analysing of CSF chemistry as a panel. In conclusion, we found that careful and methodical examination of the critical "operational" steps involved in the total testing process will reveal the 
drivers of high TAT that may have been obscured in the traditional methods of assessing TAT by only reporting the total or within-laboratory TATs. We found that the TAT for CSF chemistry testing was unacceptably high, even though this is a supposedly STAT test. Transport of the sample to the laboratory was identified to be the main cause of delay followed by delays in sample processing during the evening and night shifts. Causes such as sharing of sample and repeat testing were minor contributors. The results of this audit will be used to change pre-analytical practices in our laboratory with the aim of improving TAT and customer satisfaction.

\section{Acknowledgements}

We would like to thank Mr W Kleinhans for his assistance with data mining. This audit was conducted during an International Federation of Clinical Chemistry and Laboratory Medicine (IFCC) sponsored Professional Management Exchange Programme (PMEP) for Lucius Chidiebere Imoh and Mutale Mubanga in our laboratory. We appreciate the IFCC for the PMEP grants to two of the authors.

\section{Potential conflict of interest}

None declared.

\section{References}

1. Rajesh NT, Dutta S, Prasad R, Narang A. Effect of delay in analysis on neonatal cerebro-spinal fluid parameters. Arch Dis Child Fetal Neonatal Ed 2010;95:F25-F29. http://dx.doi. org/10.1136/adc.2008.150292.

2. Rosenling T, Stoop MP, Smolinska A, Muilwijk B, Coulier L, Shi $S$, et al. The impact of delayed storage on the measured proteome and metabolome of human cerebrospinal fluid. Clin Chem 2011;57:1703-11. http://dx.doi.org/10.1373/ clinchem.2011.167601.

3. Simonsen $A H$, Bahl JMC, Danborg PB, Lindstrom V, Larsen SO, Grubb A, et al. Pre-analytical factors influencing the stability of cerebrospinal fluid proteins. J Neurosci Methods 2013;215:234-40. http://dx.doi.org/10.1016/j.jneumeth.2013.03.011.

4. Clinical and Laboratory Standard Institute (CLSI): Quality Management System: A model for Laboratory Services: Approved Guideline - Fourth Edition. CLSI document QMS01-A4. Wayne, PA, USA, 2011.

5. International Organization for Standardization. ISO 15189:2012: Medical laboratories - requirements for quality and competence. Geneva, Switzerland: International Organization for Standardization; 2012. Available at: http:// www.iso.org/iso/catalogue_detail?csnumber=56115. Accessed January 26th 2016.

6. College of American Pathologists. Laboratory Accreditation Program. Laboratory general checklist (components GEN 20316). Available at: http://www.cap.org./apps/docs/laboratory_accreditation/checklists/laboratory_general_sep07. pdf. Accessed June 29th 2015.

7. Plebani M, Sciacovelli L, Marinova M, Marcuccitti J, Chiozza ML. Quality indicators in laboratory medicine: $A$ fundamental tool for quality and patient safety. Clin Biochem 2013;46:1170-4. http://dx.doi.org/10.1016/j.clinbiochem.2012.11.028.

8. Erasmus RT, Zemlin AE. Clinical audit in the laboratory. J Clin Pathol 2009;62:593-7. http://dx.doi.org/10.1136/ jcp.2008.056929.

9. Howanitz JH, Howanitz PJ. Laboratory results. Timeliness as a quality attribute and strategy. Am J Clin Pathol 2001;116:311-5. http://dx.doi.org/10.1309/HODY-6VTWNB36-U3L6.

10. Jones BA, Bekeris $L G$, Nakhelh RE, Walsh MK, Valenstren $P N$, College of American Pathologists. Physician satisfaction with clinical laboratory services: a College of American Pathologist Q-Probes study of 138 institutions. Arch Pathol Lab Med 2009;133:38-43.

11. Goswami B, Singh B, Chawla R, Gupta VK, Mallika V. Turn around time (TAT) as a benchmark of laboratory performance. Ind J Clin Biochem 2010;25:376-9. http://dx.doi. org/10.1007/s12291-010-0056-4.

12. Chauhan KP, Trivedi AP, Patel D, Gami B, Haridas N. Monitoring and root cause analysis of clinical biochemistry turn around time at an academic hospital. Ind J Clin Biochem 2014;29:505-9. http://dx.doi.org/10.1007/s12291-0130397-x

13. Hawkins RC. Laboratory turnaround time. Clin Biochem Rev 2007;28:179-94. 
14. Pati HP, Singh G. Turnaround time (TAT): difference in concept for laboratory and clinician. Indian J Hematol Blood Transfus 2014;30:81-4. http://dx.doi.org/10.1007/s12288012-0214-3.

15. Tamune H, Takeya H, Suzuki W, Tagashira Y, Kuki T, Honda $H$, Nakamura M. Cerebrospinal fluid/blood glucose ratio as an indicator for bacterial meningitis. Am J Emerg Med 2014;32:263-6. http://dx.doi.org/10.1016/j. ajem.2013.11.030.

16. Fouad R, Khairy M, Fathalal W, Gad T, El-Kholy B, Yorsy A. Role of clinical presentations and routine CSF analysis in the rapid diagnosis of acute bacterial meningitis in cases of negative Gram stained smears. J Trop Med 2014;213762.

17. Berry DE. Turnaround time improvement and departmentwide benefits of automation in urinalysis. Clin Leadersh Manag Rev 2006;20:E3.

18. Holland LL, Smith LL, Blick KE. Total laboratory automation can help eliminate the laboratory as a factor in emergency department length of stay. Am J Clin Pathol 2006;125:76570. $h t t p: / / d x$. doi.org/10.1309/3J5P9VJRUP4U5RU5.

19. Blick KE. Providing critical laboratory results on time, every time to help reduce emergency department length of stay: how our laboratory achieved a Six Sigma level of performance. Am J Clin Pathol 2013;140:193-202. http://dx.doi. org/10.1309/AJCPNUTIPQTRRGOD.

20. Steindel SJ, Howanitz PJ. Physician satisfaction and emergency department laboratory test turnaround time. Arch Pathol Lab Med 2001;125:863-71.

21. Kendall J, Reeves B, Clancy M. Point of care testing: randomised controlled trial of clinical outcome. BMJ 1998;316:10527. $h t t p: / / d x . d o i . o r g / 10.1136 /$ bmj.316.7137.1052.

22. Singer AJ, Ardise J, Gulla J, Cangro J. Point-of-care testing reduces length of stay in emergency department chest pain patients. Ann Emerg Med 2005;45:587-91. http://dx.doi. org/10.1016/j.annemergmed.2004.11.020.
23. McHugh ML. The Chi-square test of independence. Biochem Med (Zagreb) 2013;23:143-9. http://dx.doi.org/10.11613/ BM.2013.018.

24. Fei Y. Zeng R, Wang W, He F, Zhong K, Wang Z. National survey on intra-laboratory turnaround time for some most common routine and stat laboratory analyses in 479 laboratories in China. Biochem Med (Zagreb) 2015;25:213-21. http://dx.doi.org/10.11613/BM.2015.021.

25. Steindel SJ, Novis DA. Using outlier events to monitor test turnaround time. Arch Pathol Lab Med 1999;123:607-14.

26. Zaninotto $M$, Tasinato $A$, Padoan A, Vecchiato $G$, Pinato A, Sciacovelli L, Plebani $M$. An integrated system for monitoring the quality of sample transportation. Clin Biochem 2012;45:688-90. http://dx.doi.org/10.1016/j.clinbiochem.2012.02.013.

27. Plebani M. Quality Indicators to detect pre-analytical errors in laboratory testing. Clin Biochem Rev 2012;33:85-8.

28. Plebani M, Sciacovelli L, Aita A, Chiozza ML. Harmonization of pre-analytical quality indicators. Biochem Med (Zagreb) 2014;24:105-13. http://dx.doi.org/10.11613/BM.2014.012.

29. Ricós C, García-Victoria M, de la Fuente B. Quality indicators and specifications for the extra-analytical phases in clinical laboratory management. Clin Chem Lab Med 2004;42:57882. $h$ ttp://dx.doi.org/10.1515/CCLM.2004.100.

30. Bilwani F, Siddiqui I, Vaqar S. Determination of delay in turn around time (TAT) of stat tests and its causes: an AKUH Experience. J Pak Med Assoc 2003;53:65-7.

31. Onyenekwu CP, Hudson CL, Zemlin AE, Erasmus RT. The impact of repeat testing of common chemistry analytes at critical concentrations. Clin Chem Lab Med 2014;52:1739-45. http://dx.doi.org/10.1515/cclm-2014-0331. 